\section{Military Technical College \\ Kobry El-Kobbah, Cairo, Egypt}

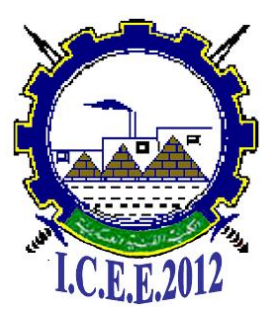

$6^{\text {th }}$ International Conference on

Chemical \& Environmental Engineering

29 -31 May, 2012.

TTEM -1

\title{
SOME FREE AIR EXPLOSION MEASUREMENT TIPS
}

\author{
Dr. Mohamed El-Naggar*
}

\begin{abstract}
Study of blast waves generated by explosions finds important application in energetic material research programs. Main tool in this aspect is recording the generated pressures at different locations and times using pressure sensors. Another important tool is the high speed digital photography recording.

Both previously mentioned tools are vital for judging the performance of EM as well as optimization of elaborated designs in several fields. In the same time, both techniques are used for improvement of adapted theoretical models simulating such processes. Pressure sensors used in blast wave pressure measurement needs special precautions ensuring sensor protection, accurate pressure recording and accurate signal transmission to recoding devices. High speed digital photography is also used for performance analysis of EM combustion or detonation as well as motion study of related processes.
\end{abstract}

In this presentation, blast pressure measurement techniques are discussed supported by some real test runs. Problems related to efficient use and maximizing information gathering from such techniques are high lighted. The presentation contains photographs of hardware used in these measuring techniques and best practices in this field are also discussed.

\footnotetext{
${ }^{*}$ Egyptian Armed Forces
} 